\title{
De novo minimal change disease after kidney transplantation
}

\author{
Amirhesam Alirezaei ${ }^{1}$, Elham Zare ${ }^{2}$, Mahmoud Parvin ${ }^{3}$, Fatemeh Nili ${ }^{4}$, Mahmood Bakhtiyari ${ }^{5,6}$ \\ ${ }^{1}$ Clinical Research Developement Center at Shahid Modarres Hospital, Department of Nephrology, Shahid Beheshti University of \\ Medical Sciences, Tehran, Iran \\ ${ }^{2}$ Department of Internal Medicine, Shahid Beheshti University of Medical Sciences, Tehran, Iran \\ ${ }^{3}$ Department of pathology, Labbafinejad Medical Center, Shahid Beheshti University of Medical Sciences, Tehran, Iran \\ ${ }^{4}$ Department of Pathology, Cancer Institute, Imam Khomeini Hospital, Tehran University of Medical Sciences, Tehran, Iran \\ ${ }^{5}$ Department of Community Medicine, School of Medicine, Alborz University of Medical Sciences, Karaj, Iran \\ ${ }^{6}$ Department of Epidemiology and Biostatistics, School of Public Health, Tehran University of Medical Sciences, Tehran, Iran
}

\section{A R T I C L E I N F O}

Article Type:

Case Report

Article History:

Received: 3 April 2017

Accepted: 10 August 2017

Published online: 29 August 2017

\section{Keywords:}

Post-transplant glomerular diseases Glomerulitis

Allograft biopsy

Minimal change disease

Anti- phospholipase A2 receptor

Membranous glomerulopathy

\begin{abstract}
A B S T R A C T
Post-transplant glomerular diseases (PTGN) have been documented frequently, although majority of them, are recurrences of primary diseases. In some cases, de novo glomerular diseases can develop in recipients. In this paper, a case of de novo minimal change disease (MCD) after non-related live donor kidney transplantation in a patient with a history of biopsy proven membranous nephropathy is described. A 25-year-old man with history of biopsy-proven idiopathic membranous glomerulopathy (MGN) who had been transplanted 3 weeks before referred to hospital, presented with peripheral edema and massive proteinuria. First kidney biopsy was compatible with acute cellular rejection with glomerulitis. The patient was treated with methylprednisolone. Panel reactive antibody (PRA) and C4d were negative. Anti- phospholipase A2 receptor (PLA2R) antibody was also negative. Another allograft biopsy was conducted and the result was highly suggestive of MCD. Thus final diagnosis was de novo MCD and proteinuria decreased successfully.
\end{abstract}

Implication for health policy/practice/research/medical education:

De novo minimal change disease after kidney transplantation in a 25 year old patient with history of biopsy proven membranous glomerulopathy (MGN) is described.

Please cite this paper as: Alirezaei AH, Zare E, Parvin M, Nili F, Bakhtiyari M. De novo minimal change disease after kidney transplantation. J Renal Inj Prev. 2018;7(2):103-106. DOI: 10.15171/jrip.2018.24.

\section{Introduction}

Glomerular disease after renal transplantation is frequently associated with recurrence of primary disease. Proteinuria remarkably diminishes long-term allograft outcome and renal function (1,2). Post-transplant glomerular diseases (PTGN) will develop in around 6\%$20 \%$ of renal allograft recipients and is either recurrence of primary disease or a de novo event (3). In one study of Canadian population, biopsy proven PTGN was observed in $24.3 \%$ of renal allografts (4). It has been reported in up to $40 \%$ of recipients. In some cases, de novo glomerular disease can occur in renal allografts. To our knowledge, de novo MCD is an infrequent complication (5-10) and only about 18 cases have been published while some of them do not completely meet the criteria for the diagnosis $(8,9)$. Clinically, patients with de novo MCD present with signs and symptoms of nephrotic syndrome shortly after renal transplantation (5-10). Pathologically it is characterized by fusion of epithelial foot processes on electron microscopy (11). We report a patient who presented with peripheral edema and massive proteinuria 3 weeks after kidney transplantation. 


\section{Case Presentation}

A 25-year-old man with history of end-stage renal disease (ESRD) due to biopsy-proven idiopathic membranous glomerulopathy (MGN) with the first presentation of $34 \mathrm{~g} / \mathrm{d}$ proteinuria and pulmonary embolism at age of 18 years, received a non-related live donor kidney transplantation in Afghanistan in November 2016. His immunosuppressive medications in the first visit included tacrolimus $1 \mathrm{mg}$ twice a day, azathioprine $50 \mathrm{mg}$ once a day and prednisolone $25 \mathrm{mg}$ daily.

Three weeks after transplantation, he presented with edema of lower extremities, abdominal distention and hypertension. The initial investigation revealed a proteinuria of $11 \mathrm{~g} / \mathrm{d}$ and a serum creatinine of $1.1 \mathrm{mg} / \mathrm{dL}$. The patient was hospitalized.

On admission, azathioprine was discontinued. Immunosuppressive regimen changed to tacrolimus $4 \mathrm{mg}$ twice a day and mycophenolate mofetil $1 \mathrm{~g}$ twice a day. The patient also was treated with anti-proteinuric agents in multimodal fashion; valsartan $80 \mathrm{mg}$ daily, spironolactone $25 \mathrm{mg}$ daily, atorvastatin $20 \mathrm{mg}$ daily and calcitriol 0.25 mg daily.

A renal allograft biopsy was conducted. Morphologic lesions consisted a severe lymphocytic tubulitis with moderate interstitial inflammation highly suggestive of acute cellular rejection. There was a severe peritubular capillaries (PTCitis) suspicious for antibody mediated
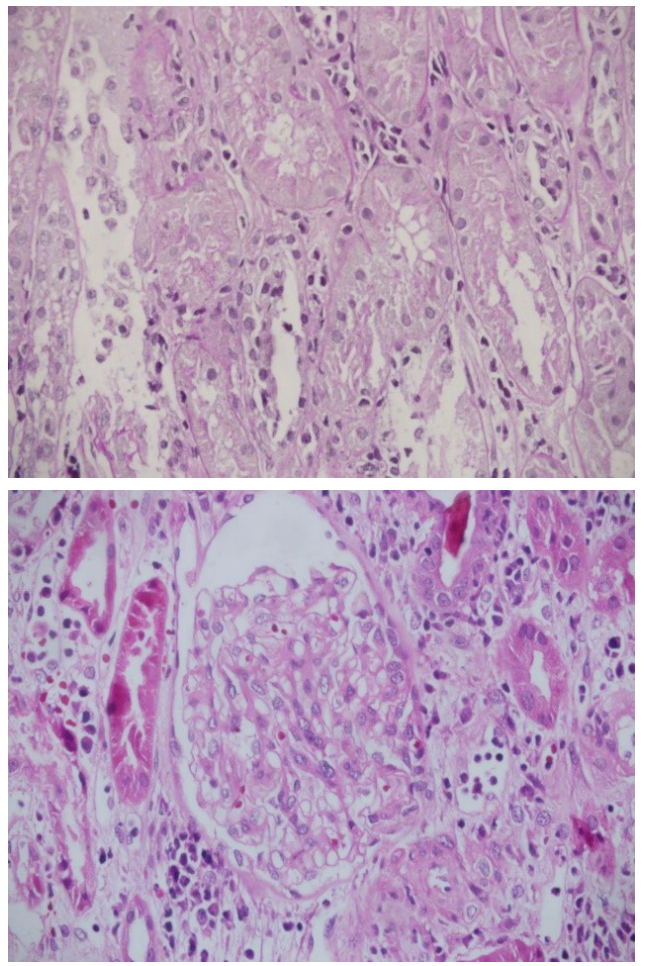

Figure 1. Light microscopy of first allograft biopsy specimen. Severe lymphocytic tubulitis with moderate interstitial inflammation highly suggestive of acute cellular rejection. Severe PTCitis is suspicious for acute antibody mediated rejection too. rejection too. There was no significant glomerulopathy in the immunofluorescence and light microscopy studies (Figure 1). C4d result was pending.

Panel reactive antibody (PRA) by flow cytometry was requested. For initial treatment patient received intravenous methylprednisolone pulse therapy $(500 \mathrm{mg}$ ) for 3 consecutive days (day 2 to day 4).

PRA result was negative and IHC (immunohistochemistry) study for C4d in the PTCs and glomeruli was negative. Additionally no immune reaction was detected on IHC (Figure 2). Anti-phospholipase-A2-receptor (PLA2R) antibody was measured due to high possibility on recurrence of MGN that was negative.

On sixth day of admission, the protein excretion decreased to $3.3 \mathrm{~g} / \mathrm{d}$, serum creatinine was stable. Peripheral edema gradually decreased.

According to morphologic lesions and clinical manifestations and laboratory correlation, a second allograft biopsy was obtained on the eighth day after first biopsy.

Microscopic examination revealed cortical kidney tissue with 12 glomeruli and 3 medium- sized arteries. All of the glomeruli, tubules, interstitium and vessels were unremarkable. Glomerulitis, GBM thickening,

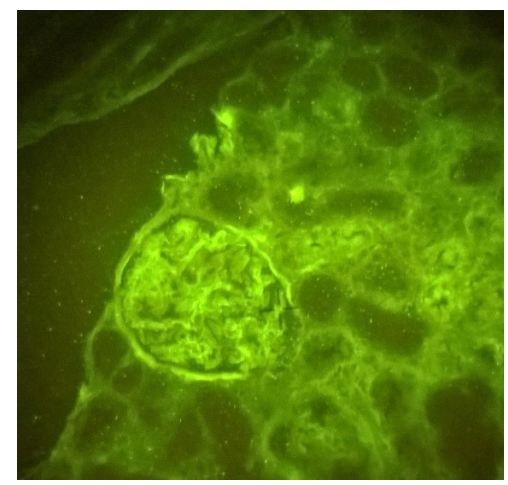

Figure 2. Immunofluorescence study without significant C4d deposition in PTCs and in glomerulus.

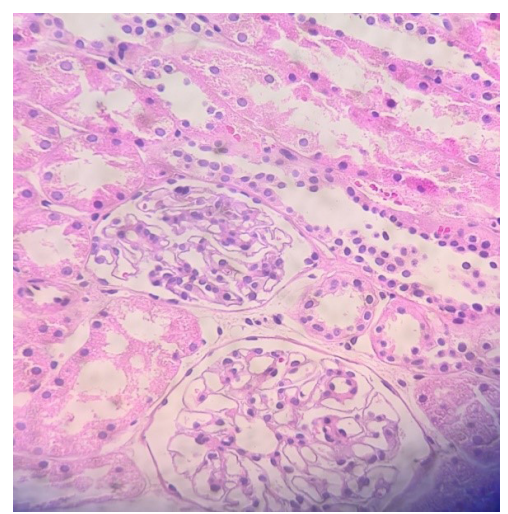

Figure 3. H\&E stained sections $(\times 400)$ showed glomeruli, tubules, and interstitium and peritubular capillaries without significant histopathological finding. 


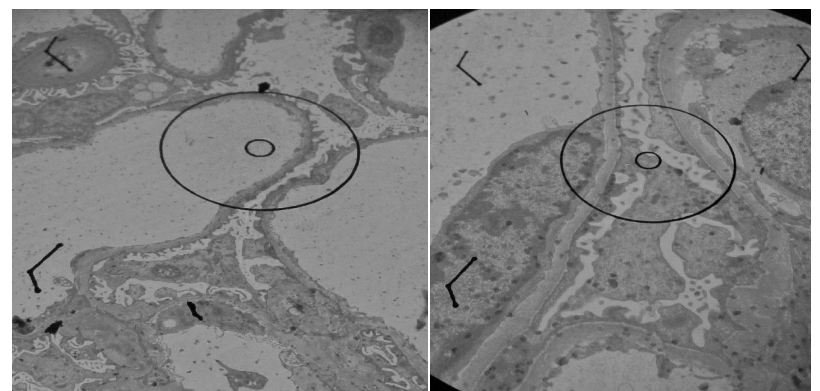

Figure 4. Electron microscopic examination shows extensive visceral foot process effacement without deposit or GBM thickening.

peritubular capillaritis, tubulitis, interstitial inflammation or endothelialitis was not detected (Figure 3). An ultrastructural examination revealed extensive effacement in $75 \%-80 \%$ of visceral foot processes. No GBM thickening, immune-complex type deposit, glomerulitis or sub-endothelial electron lucency was identified (Figure 4). These pathologic findings were highly suggestive of minimal change disease (MCD). The final diagnosis was do novo MCD.

The patient was treated with prednisolone $25 \mathrm{mg}$ daily, mycophenolate mofetil $2 \mathrm{~g}$ daily and tacrolimus $7 \mathrm{mg}$ daily (trough level was $12 \mathrm{ng} / \mathrm{mL}$ ). Patient's response was favorable. After 2 weeks of treatment, proteinuria was decreased to $100 \mathrm{mg} /$ day and peripheral edema was significantly reduced.

\section{Discussion}

PTGN can be subdivided both clinically and pathologically into three groups; true recurrence of original disease, transplant glomerulopathy with no previous histological confirmed primary disease and de novo disease which can be defined as new pathology distinguishable from the background disease (5).

Occasionally, MCD could develop de novo in renal allografts, however, in literature review only a few reports have been published (6-10).

Live donor transplant allograft is considered as a risk factor for de novo MCD as seen in our patient (8).

Like our case, most of the published cases were presented in early phases after renal transplantation (6-10,12). Zafarmand et al described 5 new cases of de novo MCD and 9 previously reported cases. Except one of them, de novo MCD occurred in no more than 4 months after transplantation (8). Acute rejection can also present as nephrotic range proteinuria shortly after transplantation (12-16).

The first allograft biopsy was highly suggestive of acute cellular rejection. Our patient had also nephrotic range proteinuria, however our first diagnosis was based on this implications.

Around $7 \%$ to $48 \%$ of $\mathrm{MGN}$ can recur after renal transplantation (17-19). Anti-phospholipase A2 receptor (PLA2R) antibody is highly specific and can be detected in more than $70 \%$ of active idiopathic MGN, and may predict its recurrence too (19). PLA2R antibody was negative in our patient and kidney biopsy finding was not compatible, hence we ruled out the recurrence of MGN. For further evaluation second allograft biopsy was conducted. Patients with de novo MCD had a broad variety of primary diseases in native kidneys. Primary disease of our patient was idiopathic MGN. Among previous published papers, 2 of them had MGN as the original disease $(9,10)$.

In most cases, de novo MCD is identified by symptoms and signs of nephrotic syndrome that has usually occurred suddenly. All of reported cases of de novo MCD had nephrotic range proteinuria and most of their renal allograft function were preserved (6-12). Our patient presented with early expulsive onset of nephrotic syndrome. The second biopsy was consistent with MCD. There is no recommendation for standard treatment of de novo MCD. Acceptable response rate to high dose steroid was reported and usually the patient will become free of proteinuria within two to three weeks. Treatment modalities included calcium channel (non-DHP) blockers, renin-angiotensin system inhibitors, lowering the dose of calcineurin inhibitors, continuing of immunosuppressive medication and starting other anti-proteinuric drugs (6-11).

Altogether, de novo MCD has been reported as a complication with a propitious prognosis. Except for a few cases, most cases of de novo MCD had responded to different treatments. Zafarmand et al reported 12 out of 14 de novo MCD cases reached complete remission while no impairment of renal allograft function was occurred (8). According to the course of the disease, we did not expect that our patient shows focal segmental glomerulosclerosis. Finally our patient had less than $100 \mathrm{mg}$ proteinuria per day with a stable kidney function and discharged accordingly.

\section{Conclusion}

In conclusion, the prognosis of de novo MCD is favorable. Significant amelioration of proteinuria with a stable renal function is detectable in most of the cases.

\section{Authors' contribution}

AA was the patient's treating physician and supervised the manuscript preparation. EZ and AA coordinated the collection of information on the patient and wrote the manuscript. MP and FN contributed to histopathological interpretation. All authors read and signed the final manuscript.

\section{Conflicts of interest}

There were no points of conflicts.

\section{Ethical considerations}

Ethical issues (including plagiarism, data fabrication, double publication) have been completely observed by the authors. The patient has given his informed consent regarding this case report. 


\section{Funding/Support}

None.

\section{References}

1. An JN, Lee JP, Oh YJ, Oh YK, Ha J, Chae DW, et al. Incidence of post-transplant glomerulonephritis and its impact on graft outcome. Kidney Res Clin Pract.2012;31:219-26. doi: 10.1016/j.krcp.2012.09.004.

2. Morozumi K, Takeda A, Otsuka Y, Horike K, Gotoh N, Watarai Y. Recurrent glomerular disease after kidney transplantation: an update of selected areas and the impact of protocol biopsy. Nephrology (Carlton). 2014;19:6-10. doi: 10.1111/nep.12255.

3. Couser W. Recurrent glomerulonephritis in the renal allograft: an update of selected areas. Exp Clin Transplant. 2005;3:283-8.

4. Chailimpamontree W, Dmitrienko S, Li G, Balshaw R, Magil A, Shapiro RJ, et al. Probability, predictors, and prognosis of posttransplantation glomerulonephritis. J Am Soc Nephrol. 2009;20:843-51.doi: 10.1681/asn.2008050454.

5. Ponticelli C, Moroni G, Glassock RJ. De novo glomerular diseases after renal transplantation. Clin J Am Soc Nephrol. 2014;9:1479-87. doi: 10.2215/cjn.12571213.

6. Gkrouzman E, Kirou KA, Seshan SV, Chevalier JM. Minimal Change Disease As A Secondary And Reversible Event Of A Renal Transplant Case With Systemic Lupus Erythematosus. Case Rep Nephro. 2015;2015:987212. doi: 10.1155/2015/987212.

7. Markowitz GS, Stemmer CL, Croker BP, D’Agati VD. De novo minimal change disease. Am J Kidney Dis. 1998;32:508-13.

8. Zafarmand AA, Baranowska-Daca E, Ly PD, Tsao CC, Choi YJ, Suki WN, et al. De novo minimal change disease associated with reversible post-transplant nephrotic syndrome. A report of five cases and review of literature. Clin Transplant. 2002;16:350-61.

9. Mochizuki $Y$, Iwata $T$, Nishikido $M$, Uramatsu $T$, Sakai H, Taguchi T. De novo minimal change disease after ABO-incompatible kidney transplantation. Clin Transplant. 2012;26 Suppl 24:81-5. doi: 10.1111/j.13990012.2012.01645.x.
10. Madhan KK, Temple-Camp CR. Late de novo minimal change disease in a renal allograft. Saudi J Kidney Dis Transpl. 2009;20:266-9.

11. Vivarelli M, Massella L, Ruggiero B, Emma F. Minimal Change Disease. Clin J Am Soc Nephrol. 2017;12:332-45. doi: $10.2215 /$ cjn. 05000516 .

12. Nongnuch A, Assanatham $M$, Sumethkul V, Chalermsanyakorn P, Kitiyakara C. Early post-transplant nephrotic range proteinuria as a presenting feature of minimal change disease and acute $\mathrm{T}$ cell-mediated rejection. Transplant Proc. 2014;46:290-4. doi: 10.1016/j. transproceed.2012.07.140.

13. Ahmad I, Abul-Ezz SR, Walker PD, Bonsib SM, Ketel B, Barri YM. Acute rejection presenting as nephrotic syndrome. Transplantation. 2000;69:2663-5.

14. Akioka K, Okamoto M, Ushigome H, Nobori S, Kozaki, $\mathrm{K}$, Kaihara $\mathrm{S}$, et al. A rare case of vascular rejection in a renal transplant recipient with nephrotic range proteinuria. Clin Transplant. 2007;21:18-22. doi: 10.1111/j.13990012.2007.00712.x.

15. Waltzer WC, Anaise D, Arbeit LA, Miller F, Weinstein SW, Rapaport FT. Allograft rejection and the nephrotic syndrome. Transplant Proc. 1985;17:1763-7.

16. Dabade TS, Grande JP, Norby SM, Fervenza FC, Cosio FG. Recurrent idiopathic membranous nephropathy after kidney transplantation: a surveillance biopsy study. Am J Transplant. 2008;8:1318-22. doi: 10.1111/j.16006143.2008.02237.x.

17. Cosyns JP, Couchoud C, Pouteil-Noble C, Squifflet JP, Pirson Y. Recurrence of membranous nephropathy after renal transplantation: probability, outcome and risk factors. Clin Nephrol. 1998;50:144-53.

18. Grupper A, Cornell LD, Fervenza FC, Beck LH Jr, Lorenz E, Cosio FG. Recurrent membranous nephropathy after kidney transplantation: treatment and long-term implications. Transplantation. 2016;100:2710-6.doi: 10.1097/tp.0000000000001056.

19. Kattah A, Ayalon R, Beck LH Jr, Sethi S, Sandor DG, Cosio FG, et al. Anti-phospholipase A(2) receptor antibodies in recurrent membranous nephropathy. Am J Transplant. 2015;15:1349-59. doi: 10.1111/ajt.13133.

Copyright (C) 2018 The Author(s); Published by Nickan Research Institute. This is an open-access article distributed under the terms of the Creative Commons Attribution License (http://creativecommons.org/licenses/by/4.0), which permits unrestricted use, distribution, and reproduction in any medium, provided the original work is properly cited. 